\title{
Stochastic Modeling TECHNOLOGY FOR GRAIN CROPS STORAGE APPLICATION: REVIEW
}

\author{
Johevajile K. Mazima ${ }^{1}$, Agbinya Johnson ${ }^{2}$, Emmanuel Manasseh ${ }^{3}$ and Shubi \\ Kaijage $^{4}$ \\ ${ }^{1,4}$ Department of Communication Science and Engineering, Nelson Mandela African \\ Institution of Science and Technology, Arusha, Tanzania \\ ${ }^{2}$ School of Information Technology and Engineering, Melbourne Institute of Technology, \\ Melbourne, Australia \\ ${ }^{3}$ Tanzania Communications Regulatory Authority, Dar es Salaam, Tanzania
}

\begin{abstract}
Stochastic modeling is a key technique in event prediction and forecasting applications. Recently, stochastic models such as the Artificial Neural Network, Hidden Markov, and Markov Chain have received a significant attention in agricultural application. These techniques are capable of predicting the actions for the better planning and management in various fields. This work comprehensively summarizes and compares their applications such as their processing techniques, performance, as well as their strengths and limitations with regard to event prediction and forecasting. The work ends with recommendations on the appropriate techniques for cereal grain storage application.
\end{abstract}

\section{KEYWORDS}

Grain storage condition, Hidden markov model, Artificial Neural Network, Markov chain \& Forecasting

\section{INTRODUCTION}

Stochastic modeling techniques have been the most significant in prediction and forecasting. These techniques have been used for estimating the probability of outcomes to predict what conditions might be under different situations [1]. Forecasting of unknown features depends on exploitation of these techniques. They largely contribute to better detection and prediction of data. Modeling techniques such as Artificial Neural Networks (ANNs), Hidden Markov and Markov Chain models have become increasingly important methods with the growth of complex computations [2,3]. Today, we are faced with the crucial problem of inefficient detecting and predicting of condition (variations of moisture contents and temperature) over the entire grain bulk [4] in the storage facility. The aim of this study is to suggest the best technique for forecasting the grain storage conditions under few given states.

\section{LITERATURE REVIEW}

Hidden Markov (HMMs), Artificial Neural Networks (ANNs), and Markov Chains (MC) models are popular tools for modelling dependent random variables in diverse areas [5] such as speech processing and enhancement [6], audio segmentation [7], DNA recognition [8], fault [9], and rainfall occurrence [10]. These are based on a stochastic process [11] in which a chain produces an unobservable state that can be inferred only through another set of stochastic process. Previous studies on weather condition and crop activity show that forecasting using stochastic techniques is a highly researched area as shown in Table 1 to 2 , though

DOI: $10.5121 /$ ijaia.2016.7603 
not enough has been done for crop grain storage. In Figure 1 and 2, the frequency of publications in the area of weather condition and crop activity forecasting published between 2008 and 2016 respectively are demonstrated as reviewed in this study.

\subsection{Artificial Neural Networks (AnNS)}

For crop activities as demonstrated in Table 2, the study [12] presented a neural network approach in which the classification of rice varieties was estimated. An overall classification accuracy obtained was $92 \%$. Wheat seeds classification using ANN was also estimated whereby the method was found to be effective for recognizing wheat varieties [13]. The study [14] showed that back propagation neural network (BPNN) provided more correct wheat classification at $90 \%$ than discriminant analysis which was at $83.33 \%$. Further [15] illustrated how Multi layer perceptron back propagation with image processing algorithm gave higher wheat seeds classification accuracy which was at 95\%. It was presented in [16] that ANN approach was capable of predicting wheat production under different conditions and farming systems using direct and indirect technical factors. Moreover, three terms ANN back propagation network was proposed as a predicting tool for moisture content on maize. The model outweighed the two terms back propagation with the proportional factor which increased the convergence speed and reduced learning stalls [17]. The study [18] presented the artificial neural network method in which the equilibrium moisture content of maize was predicted. Maize needed less energy at higher moisture content (above 11\% d.b.) for drying and storing, but at lower moisture contents more energy was needed. Artificial Neural Networks (ANN) analysis was also carried to predict the extent of shelled corn shrinkage. The method was found to be most appropriate for prediction capability of shrinkage [19]. It was also reported in [20] that generic approach for collective prediction of moisture sorption isotherms (MSI) for 12 cereals and 5 legumes using artificial neural networks was an effective, reliable, and fast method for the collective prediction of MSIs for several grains and legumes simultaneously.

For weather condition as shown in Table 1, the study [21] reported the prediction of rainfall over Udupi District of Karnataka in India through artificial neural network. The method used three layered networks of different number of hidden neurons. In [22] rainfall prediction suggested that the ANN model could be an important tool for local rain forecasting, although it cannot replace the forecasters' experience. It was also reported in [23] that rainfall prediction by combining wavelet technique with ANN gave high accuracy. Moreover, the study [24] presented that ANN with linear transfer function (LTF), and fuzzy rule-based techniques was developed for the prediction of rainfall runoff for Narmada catchment up to Manot gauging site. The other study [25] presented the rainfall runoff modeling using Modular ANN with singular spectrum analysis. In the study [26], an artificial neural network (ANN) approach to forecasting future precipitation was proposed. It was done through spatial downscaling and constructing new intensity durationfrequency (IDF) curves with climate change into consideration using a temporal downscaling method. It was reported in [27] that neural network algorithms with wavelet transformation for daily precipitation predictions provided significant advantages for estimation process.

\subsection{MARKov CHAIN (MC)}

Few studies have been conducted on crop activities forecasting using Markov chain model as shown in Table 2. Studies reviewed in this work are of between 2008 and 2016. There are few studies that have used Markov chain model for crop activities and average for weather condition are very few as demonstrated in Figure 5 and 6. In this work [28], Markov chain model was used to predict the crop grown on a field when the crops grown in the previous 3-5 years are known. The obtained results showed that the proposed approach was able to predict the crop type of each field, before the beginning of the crop season, with accuracy of $60 \%$, which was better than the 
results obtained with approaches based on remote sensing imagery. Non-stationary Markov chain with logistic regression was also used to model dynamics of crop rotation [29].

Some of studies presented the weather forecasting as shown in Table 1. Among them include: estimation of the rainfall sequences during the rainy season in Kurdufan [30], rainfall prediction at the Daspalla Region in Odisha, Eastern India [31] for crop planning, daily rainfall occurrence forecasting in Peninsular Malaysia [32], the rainfall estimation during monsoon season over major station in Gangetic West Bengal [33], and a stochastic generator of monthly rainfall series

in Tunisia [34]. In the study [35], Markov chain model with weights was applied to predict Standardized Precipitation Index (SPI) drought intensity by using standardized self coefficients as weights. However, the forecasting ability was weak when there was a sharp change or an increase in drought intensity. Analysis of hydrological drought characteristics showed that the expected frequency of drought occurrence was higher for smaller time scales (i.e., 3-month and 6-month) [36]. Moreover, other works presented the wet and dry patterns of daily precipitation in Colombo [37]. The method also can be used to investigate the return periods of long wet and dry spells. However, the accuracy of modeling wet spells found to be high compared to dry spells. Markov chain was also used to know the dry and wet spell distribution at Varanasi in Uttar Pradesh whereby a week period was considered as the optimum length of time [38]. The study [39] presented daily temperature prediction from correlated categorical data sequence in Taipei, Taiwan. The proposed method gave higher average forecasting accuracy.

\subsection{Hidden MARKov MODEL (HMM)}

For crop activities as shown in Table 2, the study [40] found that the rate for single insect with normal pattern was about $98 \%$, while for lateral position single insect was about $87 \%$. In this work [41], a general framework of Hidden Markov Models (HMMs) based corn progress percentage estimation method was also presented. The results demonstrated the feasibility of proposed solutions on corn progress percentage estimation in the state-level. Moreover, the optimum growth states and atmospheric conditions were determined using the Viterbi algorithm in HMM.

For weather condition as demonstrated in Table 1, the study [42] presented modeling of winter rainfall occurrence using the hidden markov model. The hidden states were assumed to be an unknown random function of slowly varying climatic modulation of the winter jet stream and moisture transport dynamics. In the study [43], modeling of a homogeneous hidden markov model on the northeast rainfall monsoon using 40 rainfall stations in Peninsular, Malaysia for the period of 1975 to 2008 was also presented. The model assessed the behaviour of rainfall characteristics with large scale atmospheric circulation. It was reported in [44] that nonhomogeneous hidden Markov model was utilized to investigate potential changes in Indian monsoon summer rainfall, comparing with the 2070-2099 period with the second half of the twentieth century. The persistence level of Kuantan daily rainfall prediction was reported in [45]. It was done using the hybrid of autoregressive fractional integrated moving average (ARFIMA) and hidden Markov model (HMM). Moreover, it was presented in [46] that the hidden markov model was used for analyzing the spatiotemporal characterization of droughts at different severities. Another work [47] presented the development of the hidden markov model for assessing the drought characteristics in India using monthly precipitation and streamflow data. Moreover, Homogenous Hidden Markov Models (HMMs) were also developed for forecasting droughts using the Standardized Precipitation Index, SPI, at short-medium term [48]. Furthermore, the paper [49] reported a constrained Hidden Markov Model for evaluating a session of precipitation series. The method was capable of checking the quality of precipitation series instead of manual way. 
International Journal of Artificial Intelligence and Applications (IJAIA), Vol. 7, No. 6, November 2016

Table 1. Key Points of Survey on Weather Condition Forecasting Techniques

\begin{tabular}{|l|l|l|}
\hline \multicolumn{1}{|c|}{ Main focus } & \multicolumn{1}{c|}{ Method } & \multicolumn{1}{c|}{ References } \\
\hline Rainfall runoff modeling & ANN & {$[24,25]$} \\
\hline Precipitation downscaling forecasting & ANN & {$[26]$} \\
\hline Daily precipitation predictions & ANN & {$[27]$} \\
\hline Rainfall prediction & ANN & {$[21-23]$} \\
\hline Rainfall forecasting & MC & {$[30-34]$} \\
\hline Drought occurrence prediction & MC & {$[35,36]$} \\
\hline Dry and wet spell distribution & MC & {$[38]$} \\
\hline Description of wet and dry pattems of weather & MC & {$[37]$} \\
\hline Temperature prediction & MC & {$[39]$} \\
\hline Rainfallmodeling & HMM & {$[42-45]$} \\
\hline Drought forecasting & HMM & {$[46-48]$} \\
\hline Anomaly detection of precipitation series & HMM & {$[49]$} \\
\hline
\end{tabular}

Table 2. Key Points of Survey on Crop Activities Forecasting Techniques

\begin{tabular}{|c|c|c|}
\hline Main Focus & Method & References \\
\hline Predicting wheat production & ANN & {$[16]$} \\
\hline Classification of Rice Grains & ANN & [12] \\
\hline Identification of Stored Grain Age & ANN & [14] \\
\hline Moisture Prediction in Maize & ANN & {$[17,18]$} \\
\hline $\begin{array}{l}\text { Determining moisture sorption isotherms of cereal grains and } \\
\text { legumes }\end{array}$ & ANN & {$[20]$} \\
\hline Predicting the capability Shelled com shrinkage & ANN & [19] \\
\hline Wheat Seeds Classification & ANN & {$[13,15]$} \\
\hline Predicting the crop type of each field for crop rotation & $\mathrm{MC}$ & [28] \\
\hline Crop rotation modeling & $\mathrm{MC}$ & [29] \\
\hline Stored grain insect Image processing & HMM & [40] \\
\hline Estimation of Com Progress Stages & HMM & [41] \\
\hline
\end{tabular}

\subsection{Strengths And Limitation Of Forecasting TeChniQueS}

A number of strengths and limitations of forecasting techniques have been identified in this work as summarized in Table 3 [50-69]. Markov Chain Model (especially first order Markov Chain) with some of the data is insufficient to estimate reliable probability. Because it may not be possible to observe sufficient transitions from a given transient set of states to a closed state where this transition is dependent on a rare climatic event, the value of this parameter is of vital importance in the dynamics of the community. Also, validation of the Markov model depends on predictions of system behaviour over time, and it is; therefore, frequently difficult, and may even be impossible for really long period of time [70]. HMM is flexible with fewer computations compared to artificial neural network model [71, 72]. However, HMM algorithm [73, 74] (forward backward or viterbi) presents poor discriminative power because it bases on the Maximum Likelihood (ML) criterion, which is itself non-discriminative. HMM [75] is explainable and has solid statistical foundation. It shows potentials for time series prediction. 
Table 3. Strengths and Limitations of Modeling Techniques

\begin{tabular}{|c|c|c|c|}
\hline & ANN & HMM & MC \\
\hline \multirow[t]{4}{*}{ Strengths } & $\begin{array}{l}\text { Independent on the } \\
\text { statistical distribution }\end{array}$ & $\begin{array}{l}\text { Performs linear } \\
\text { relationship }\end{array}$ & $\begin{array}{l}\text { Effective in modeling } \\
\text { time series }\end{array}$ \\
\hline & Nonlinearity & $\begin{array}{l}\text { Dynamic relationship } \\
\text { Powerful optimization } \\
\text { algorithms (EM) }\end{array}$ & $\begin{array}{l}\text { Effective in modeling } \\
\text { categorical data } \\
\text { sequences }\end{array}$ \\
\hline & Discriminative & $\begin{array}{l}\text { Computational } \\
\text { intractability inferring } \\
\text { hidden state form } \\
\text { observation }\end{array}$ & $\begin{array}{l}\text { Solves several linear } \\
\text { programming problems }\end{array}$ \\
\hline & $\begin{array}{l}\text { Rich in complex } \\
\text { computation }\end{array}$ & $\begin{array}{l}\text { Deals well with } \\
\text { sequential structures }\end{array}$ & $\begin{array}{l}\text { Evaluates system } \\
\text { reliability well }\end{array}$ \\
\hline \multirow[t]{5}{*}{ Limitations } & $\begin{array}{l}\text { Lack of interpretability } \\
\text { Lack of a set of } \\
\text { methods for optimizing } \\
\text { the network structure }\end{array}$ & $\begin{array}{l}\text { Inefficient and difficult } \\
\text { to interpret for many } \\
\text { states }\end{array}$ & $\begin{array}{l}\text { Does not predict the } \\
\text { future from the observed } \\
\text { events }\end{array}$ \\
\hline & $\begin{array}{l}\text { Unable for linear } \\
\text { computation } \\
\text { Cannot perform better } \\
\text { for independent } \\
\text { stochastic event }\end{array}$ & $\begin{array}{l}\text { Fully-connected } \\
\text { transition diagramcan } \\
\text { lead to severe } \\
\text { overfitting }\end{array}$ & $\begin{array}{l}\text { Computational } \\
\text { limitations }\end{array}$ \\
\hline & $\begin{array}{l}\text { Over training of } \\
\text { network }\end{array}$ & $\begin{array}{l}\text { Lack of global context } \\
\text { for modeling }\end{array}$ & $\begin{array}{l}\text { Slow convergence rates } \\
\text { and very slow }\end{array}$ \\
\hline & $\begin{array}{l}\text { Extrapolation error A } \\
\text { great computation } \\
\text { burden overfitting }\end{array}$ & $\begin{array}{l}\text { Require the initial } \\
\text { assumption for the } \\
\text { statistical distributions }\end{array}$ & $\begin{array}{l}\text { The amount of } \\
\text { computations increases } \\
\text { rapidly with the amount } \\
\text { of states }\end{array}$ \\
\hline & $\begin{array}{l}\text { Black box in nature } \\
\text { Unclear relationships } \\
\text { between the outcome } \\
\text { and the predictors }\end{array}$ & $\begin{array}{l}\text { The number of hidden } \\
\text { states must be set a } \\
\text { priori so that model } \\
\text { complexity is not } \\
\text { inferred from data in a } \\
\text { bayesian way }\end{array}$ & $\begin{array}{l}\text { Model is often not } \\
\text { structurally similar to } \\
\text { the physical or logical } \\
\text { organization of the } \\
\text { system }\end{array}$ \\
\hline
\end{tabular}

\section{ForeCASTING TEChNIQUES}

\subsection{Artificial Neural Networks Model}

Artificial Neural Networks (ANNs) model is the mathematical tool which is used to simulate and solve complex problems. It is based on the powerful thought ability of the human brain. It is applied to various applications such as industry, health, electronics, finance, chemistry, statistics, agriculture, automotive and cognitive sciences. ANNs are described by their modular structure, learning capability, prediction performance, and internal non-linearity. As human brain, artificial neural network also has neurons with many inputs as human brain synapses as demonstrated in Figure 1. Its neuron has the simple model with three functions such as multiplication, summation, and activation. Each input of a neuron is multiplied by the weight at the entrance. Then, it sums up all weighted inputs and bias. At last, the mathematical model determines the activation level of the neuron using the transfer function as shown in Figure 2. This is done once the activation level exceeds the threshold value $[76,77]$. 
International Journal of Artificial Intelligence and Applications (IJAIA), Vol. 7, No. 6, November 2016

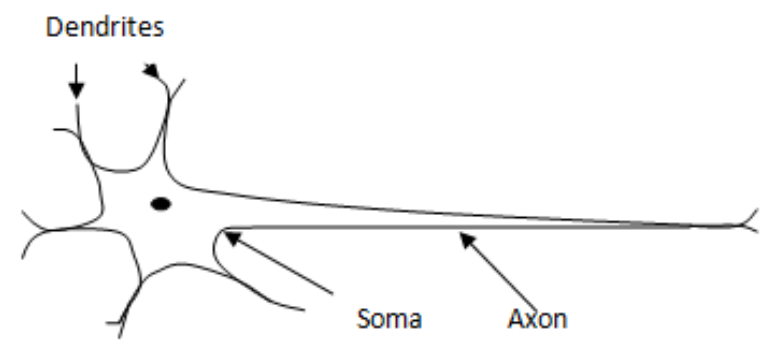

Figure 1. Biology Neuron [78]

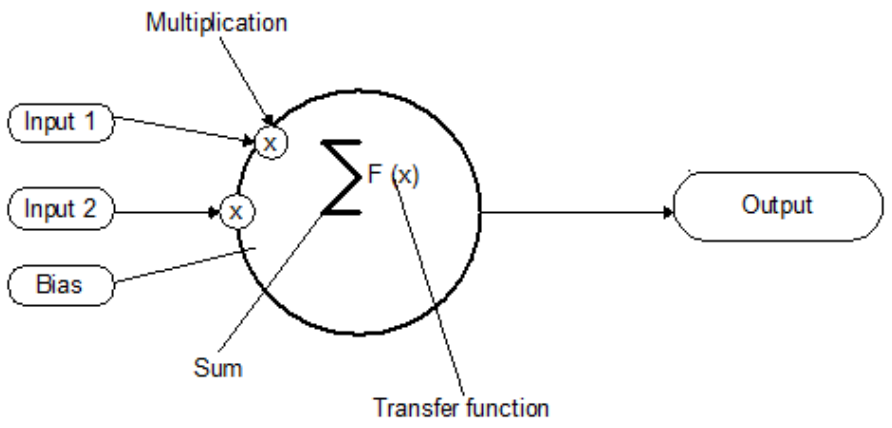

Figure 2. Artificial Neuron [78]

ANN mode has architecture which consists of three neuron layers such as input, hidden and output layers as shown in Figure 3. The first layer has input neurons that send information through synapses to the second layer of neurons. Then, they pass through more synapses to the third layer of output neurons $[79,80]$.

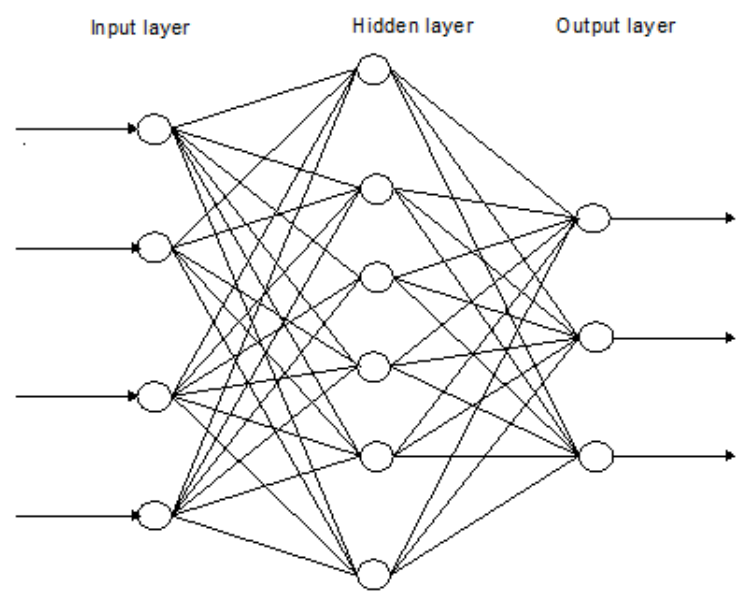

Figure 3. ANN Structure [81] 


\subsection{Markov Chain Model}

A Markov chain is a mathematical model of a random observable fact with time that the past affects the future only through the present. The time can be discrete or continuous. It works basing on Markov property. It has a finite set of possible states and transitions among them. These are governed by a set of conditional probabilities of the next state given the present one $[82,83]$.

Markov Property: The Markov property states that the conditional probability distribution for the system at the next step depends only on the current state of the system, and not the state of the system at previous steps.

A Markov chain is defined by a transition probability parameter (aij) associated with each transition (arrow) and determines the probability of a certain state $(\mathrm{Sj})$ following another state (Si). The state probabilities are well defined below [84, 85]:

It has a finite set of states, $S_{1}, S_{2} \ldots S_{N}$, a set of transition probabilities:

$$
a_{i j}=P\left(q_{t+1}=S_{j} \mid q_{t}=S_{i}\right)
$$

The initial state probability distribution is given as:

$$
\pi_{i}=P\left(q_{0}=S_{i}\right)
$$

\subsection{HidDEN MARKOV MODEL (HMM)}

Hidden Markov Model (HMM) is an extension of the Markov Chain. It is the simplest dynamic bayesian distribution over sequences of observations. It is described as a 5-tuple $\lambda=\left(\mathrm{q}, \sum, \pi, \mathrm{A}\right.$, B). The states q are hidden. Probabilities A are state transition probabilities that indicate the chance that a certain state change might occur. Probabilities $\pi$ are the initial state transition probabilities. Each state has a set of possible emissions $\sum$. Probabilities B are observation probabilities for the emissions. HMM applies the Markovian property. In every state, a Markov chain can be observed directly. But sometimes there is a sequence of a state that wants to be known but cannot be observed directly but through the observable state as shown in Figure 4. That is why it is called the hidden Markov model[86, 87].

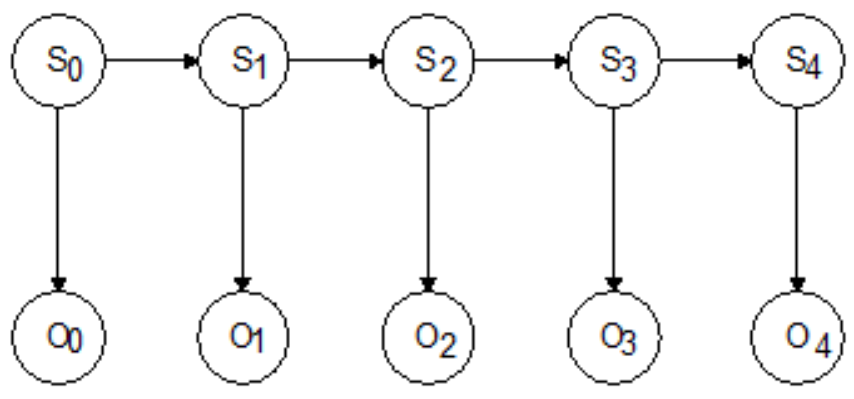

Figure 4. HMM Topology [88]

The HMM states $[89,90]$ are described as:

$\mathrm{N}$ is the number of hidden states in the model. The individual states are denoted as: 
International Journal of Artificial Intelligence and Applications (IJAIA), Vol. 7, No. 6, November 2016

$$
S=\left\{s_{1}, s_{2}, \ldots, s_{N}\right\}
$$

This is done at the length $\mathrm{t}$ as Qt.

$\mathrm{M}$ is the number of distinct observation symbol per hidden state. The individual symbols are denoted as:

$$
V=\left\{v_{1}, v_{2}, \ldots, v_{M}\right\}
$$

It is also done at the length $\mathrm{t}$ as Qt.

The state transition probability matrix is described as:

$$
[A]_{i j}=\{a\}_{i j}
$$

Whereas, $a_{i j}=P\left(Q_{t+1}=s_{j} \mid Q_{t}=s_{i}\right), 1 \leq \mathrm{i}, \mathrm{j} \leq \mathrm{N}$

The observation symbol probability in hidden state $\mathrm{j}$ is also described as:

$$
[B]_{j k}=\left\{b_{j}\left(v_{k}\right)\right\}
$$

Where, $b_{j}\left(v_{k}\right)=P\left(O_{t}=v_{k} \mid Q_{t}=s_{j}\right)$

$$
1 \leq \mathrm{j} \leq \mathrm{N}, 1 \leq \mathrm{k} \leq \mathrm{M}
$$

The initial state distribution is given as:

$$
\Pi=\left\{\pi_{i}\right\}
$$

Where, $\pi_{i}=P\left(Q_{1}=s_{i}\right) 1 \leq \mathrm{i} \leq \mathrm{N}$

Once the HMM is given appropriate values of $\mathrm{N}, \mathrm{M}, \mathrm{A}, \mathrm{B}$, and $\pi$, it can be used as a generator to a given observation sequence:

$$
O=\left\{O_{1} O_{2} \ldots O_{T}\right\}
$$

Where, $\mathrm{T}$ is the number of observations in the sequence. For simplicity, using the compact notation $[86,87,91]$ :

$$
\lambda=(A, B, \pi)
$$

\subsubsection{Hmm Main Problem Solving StepS}

The HMM architecture usually is automated with integrated stochastic processes using solving techniques such as evolution, decoding and Leaning.

\subsubsection{EVOLUTION}

This is an algorithm process in HMM with a sequence of observations, $P(O \mid \lambda)$. The probability of the observation sequence given a model can be computed [86,91]. One of the efficient algorithms for evolution solution is the Forward algorithm.

In evolution if the process in the HMM is a first order Markov Chain, the probabilities of the system in particular state $s(t)$ at time $t$ depends on its state at $s(t-1)[86,87,91,92]$. The 
probability of the HMM being in state $\mathrm{s}_{\mathrm{j}}$ at time $\mathrm{t}$ having generated the first $\mathrm{t}$ emission that is the partial probability $\alpha \mathrm{j}(\mathrm{t})[86,87,92]$ :

$$
\alpha_{j}(t)= \begin{cases}0 & , t=0 \text { and } j \neq \text { initial state } \\ 1 & , t=0 \text { and } j=\text { initial state } \\ {\left[\sum_{i} \alpha_{i}(t-1) a_{i j}\right] b_{j k} v(t), \quad \text { Otherwise }}\end{cases}
$$

\subsubsection{DECODING}

This is the algorithm that produces the most probable sequence of hidden states given some observations [90, 93]. It applies viterbi algorithm, which is also a trellis algorithm. It is very similar to the forward algorithm, except that the transition probabilities are maximized at each step instead of being summed [90, 93]. It is a simple and efficient decoding technique.

\subsubsection{LEARNING}

Learning is the process that calculates the Markov model on state transition and emission matrices that have generated a sequence of observations. The process has supervised and unsupervised trainings. If the training contains both the inputs and outputs of a process, supervised training can be performed by equating inputs to observations and outputs to states. But if only the inputs are provided in the training data, then unsupervised training is used to guess a model that may have produced those observations $[86,94,95]$.

The baum welch algorithm is the mostly used method in the learning technique. This is also known as forward backward algorithm. It gives the probabilities that the model is in state $\mathrm{s}_{\mathrm{i}}(\mathrm{t})$ as [87]: These probabilities are the partial in equation (17) and backward probabilities in equation (18).

$$
\beta_{i}(t)= \begin{cases}0 & , s_{i}(t) \neq s_{0}(t) \text { and } t=T \\ 1 & , s_{i}(t)=s_{0}(t) \text { and } t=T \\ \sum_{i} \beta_{j}(t+1) a_{i j} b_{j k} v(t+1), \text { Otherwise }\end{cases}
$$

Since, $\alpha_{\mathrm{i}}(\mathrm{t})$ and $\beta_{\mathrm{i}}(\mathrm{t})$ are just estimates for the calculation of an improved of these estimates the auxiliary $\gamma_{\mathrm{ij}}(\mathrm{t})$ quantity is introduced [87, 91]:

$$
\gamma_{i j}(t)=\frac{\alpha_{i}(t-1) a_{i j} b_{j k} \beta_{j}(t)}{p\left(V^{T} \mid \lambda\right)}
$$

Using the auxiliary quantity, an estimated version $a_{\mathrm{ij}}$ of $\mathrm{a}_{\mathrm{ij}}$ can now be calculated by $[87,91,92]$ :

$$
\hat{a}_{i j}=\frac{\sum_{t=1}^{T} \gamma_{i j}(t)}{\sum_{t=1}^{T} \Sigma_{k} \gamma_{i k}(t)}
$$

Similarly, an estimated version $b_{\mathrm{jk}}$ of $b_{\mathrm{jk}}$ can be given as $[87,91,92]$ :

$$
b_{j k}=\frac{\sum_{t=1, v(t)}^{T} \sum_{l} \gamma_{j} l(t)}{\sum_{t=1}^{T} \Sigma_{l} \gamma_{j} l(t)}
$$


International Journal of Artificial Intelligence and Applications (IJAIA), Vol. 7, No. 6, November 2016

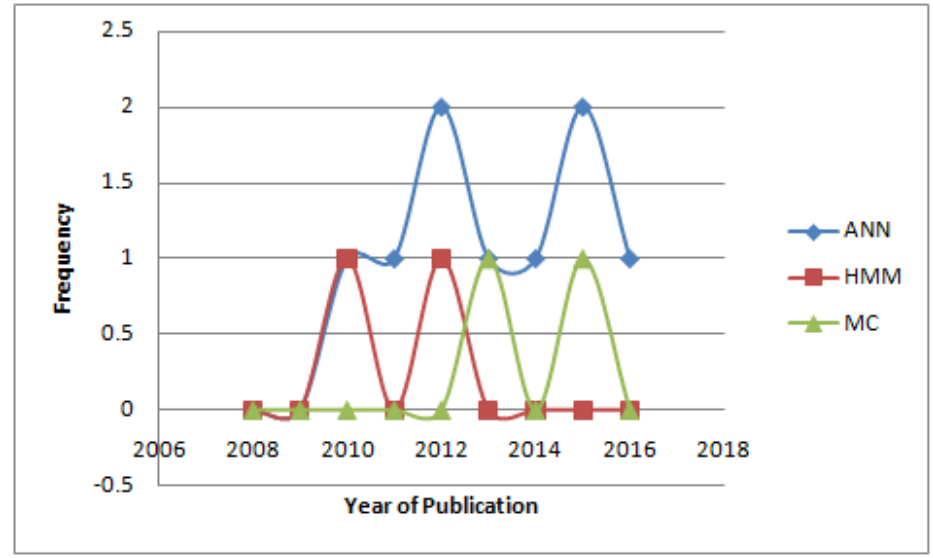

Figure 5. Studies of Modeling Techniques on Crop Activities

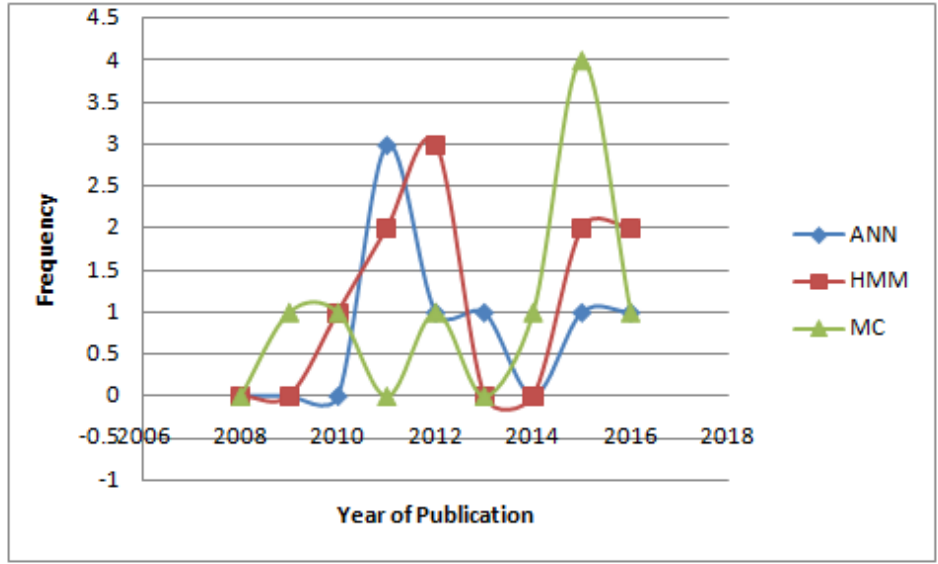

Figure 6. Studies on Weather Condition Analysis

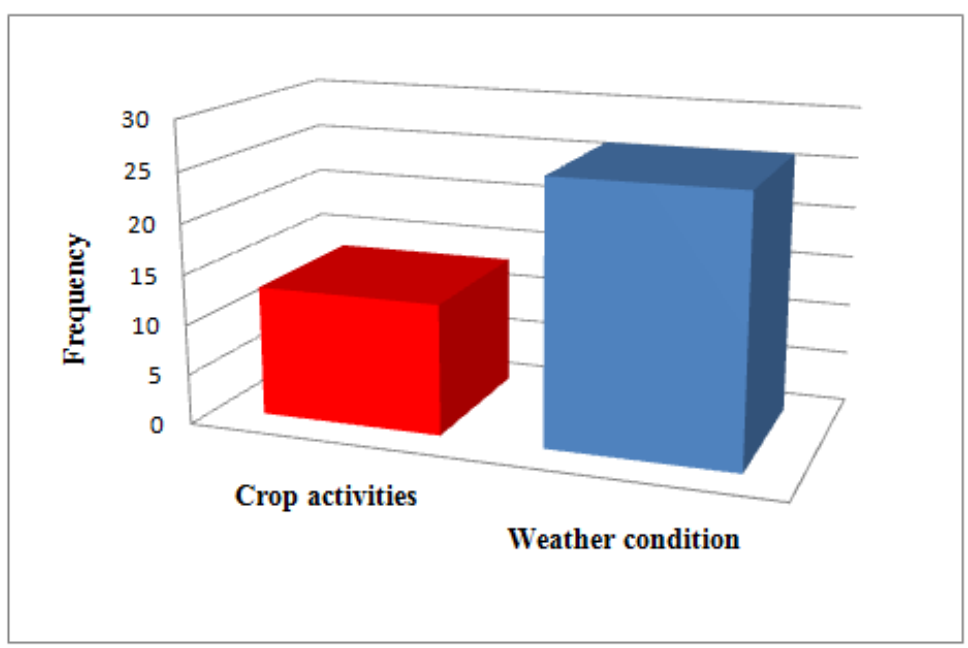

Figure 7: Activities Forecasted using Modeling Techniques Between 2008 and 2016 
International Journal of Artificial Intelligence and Applications (IJAIA), Vol. 7, No. 6, November 2016

\section{DiscuSSION AND CONCLUSION}

From literature and as reviewed in this work, the weather condition forecasting dominates crop activities as demonstrated in Figure 7. This indicates a positive of stochastic models for environment monitoring. Table 3 indicates that Artificial Neural Network (ANN) is applied only to non-linearly separable classes. It has the black box nature that causes greater computation burden on the hardware infrastructure available for the analysis. This is a great disadvantage to many systems. Unlike the Hidden Markov Model, it predicts not yet observed states. However, it has a superior capability over other models in complex computations and convergence. The Markov Chain Model (MC) does not allow the prediction of hidden states since it is limited to emission probability. The Hidden Markov Model (HMM) allows different types of states to be defined such as hidden states and observation states in connection with the normal and emission probabilities. It always models conditional dependencies of (predicts) hidden states from observed states. Therefore, the sequence of states visited is hidden. Unlike in the Markov Chain, there is no longer a one to one correspondence between states and output symbols. In the HMM, the same symbol may be emitted by more than one state and a state can emit more than one symbol.

The published papers with applications of ANN, HMM, and MC for weather condition and crop activities were reviewed in this work. All these technologies proved to have given solutions for crop planning, weather prediction, moisture detection, temperature estimation, as well as crops and seeds classification. But, the reviewed studies have confirmed that the condition forecasting of crop storage is not yet seriously researched. For this reason, these modeling techniques can be introduced in grain storage application whereby the storage condition must be forecasted basing on the variations of temperature and moisture contents. Artificial Neural Network and Hidden Markov models have enormous advantages over other models, like Markov Chain Model for their ability to learn the environment. Hence they are better models. Either ANN or HMM or both are highly recommended to be applied in grain storage condition forecasting. Since the HMM is a less computational and flexible model, it might be the best option for the grain storage condition when few states are needed to be computed.

\section{REFERENCES}

[1] J. Duan (2015) An Introduction to Stochastic Dynamics: Cambridge University Press.

[2] G. P. Zhang, (2003) "Time series forecasting using a hybrid ARIMA and neural network model," Neurocomputing, Vol. 50, pp. 159-175.

[3] E.de Souza e Silva, R.M.M. Le ao \&Richard R. Muntz, (2011) "Performance evaluation with hidden markov models," in Performance Evaluation of Computer and Communication Systems. Milestones and Future Challenges, ed: Springer, Vol. 6821, pp. 112-128.

[4] N. Deshpande and A. Shaligram, (2012) "Study of Mobile Node Based Coverage Recovery Process for WSN Deployed in Large Food Grain Warehouse," International Journal of Advances in Engineering \& Technology, Vol. 5, pp. 422-429.

[5] S. Isojunno and P. J. Miller, (2016) "Hidden Markov models capture behavioral responses to suctioncup tag deployment: a functional state approach to behavioral context," in The Effects of Noise on Aquatic Life II, ed: Springer,Vol. 875, pp. 489-496.

[6] A. Kato and B. Milner, (2014) "Using hidden Markov models for speech enhancement," in Interspeech, pp. 2695-2699.

[7] A Bietti, F Bach \& A Cont, (2015) "An online EM algorithm in hidden (semi-) Markov models for audio segmentation and clustering," in IEEE International Conference on Acoustics, Speech and Signal Processing (ICASSP).

[8] D. Xiong, R. Liu, F. Xiao \& X. Gao, (2014) "ProMT: Effective Human Promoter Prediction Using Markov Chain Model Based on DNA Structural Properties," NanoBioscience, IEEE Transactions on, Vol. 13, pp. 374-383. 
[9] F. Wang, S. Tan, Y. Yang, \& H. Shi, (2016) "Hidden Markov Model-based Fault Detection Approach for Multimode Process," Industrial \& Engineering Chemistry Research, Vol. 55, pp 4613 - 4621.

[10] C. Francesco, D. Naresh, M. Alessandro \& L. Upmanu, (2013) "Stochastic Downscaling of Daily Rainfall: Analysis of future hydroclimatic changes and their impact on the Pontinia plain using Nonhomogeneous Hidden Markov Model and Dynamic Hierarchical Bayesian Network Model," in EGU General Assembly Conference Abstracts, p. 2319.

[11] N. I. Ramesh, R. Thayakaran \& C. Onof, (2013) "Multi-site doubly stochastic Poisson process models for fine-scale rainfall," Stochastic Environmental Research and Risk Assessment, Vol. 27, pp. 1383-1396.

[12] C. S. Silva \& U. Sonnadara, (2013) "Classification of rice grains using neural networks," in Proceedings of Technical Sessions, pp. 9-14.

[13] A. Yasar, E. Kaya \& I. Saritas, (2016) "Classification of Wheat Types by Artificial Neural Network," International Journal of Intelligent Systems and Applications in Engineering, Vol. 4, pp. 12-15.

[14] B. Zhou, J. Wang \& Jinfeng Qi, (2012) "Identification of different wheat seeds by electronic nose," International Agrophysics, vol. 26, pp. 413-418.

[15] N. A. Abdullah \& A. M. Quteishat, (2015) "Wheat Seeds Classification using Multi-Layer Perceptron Artificial Neural Network",Vol. 6, pp 306-309.

[16] M. Safa, S. Samarasinghe \& M. Nejat, (2015) "Prediction of Wheat Production Using Artificial Neural Networks and Investigating Indirect Factors Affecting It: Case Study in Canterbury Province, New Zealand," Journal of Agricultural Science and Technology, vol. 17, pp. 791-803.

[17] A. Said Jadid, S. Siti Mariyam \& S. Roselina, (2012) "Moisture prediction in maize using three term back propagation neural network," International Journal of Environmental Science and Development, Vol. 3, p. 199.

[18] R. Chayjan \& M. Esna-Ashari, (2010) "Modeling of heat and entropy sorption of maize (cv. Sc704): neural network method," Res. Agr. Eng, Vol. 56, pp. 69-76.

[19] L. Momenzadeh \& A. Zomorodian, (2011) "Study of shelled corn shrinkage in a microwave-assisted fluidized bed dryer using artificial neural network," International Journal of Agriculture Sciences, Vol. 3, p. 150.

[20] M. Al-Mahasneh, F. Alkoaik, A. Khalil, A. Al-Mahasneh, A. El-Waziry, R. Fulleros \& T. Rababah , (2014) "A generic method for determining moisture sorption isotherms of cereal grains and legumes using artificial neural networks," Journal of Food Process Engineering, Vol. 37, pp. 308-316.

[21] K. Abhishek, A. Kumar, R. Ranjan \& S. Kumar, (2012) "A rainfall prediction model using artificial neural network," in Control and System Graduate Research Colloquium (ICSGRC), 2012 IEEE, pp. 82-87.

[22] A. H. El-Shafie, A. El-Shafie, H. G. El Mazoghi, A. Shehata \& M. R. Taha, (2011) "Artificial neural network technique for rainfall forecasting applied to Alexandria, Egypt," International Journal of Physical Sciences, Vol. 6, pp. 1306-1316.

[23] R. V. Ramana, et al., (2013) "Monthly rainfall prediction using wavelet neural network analysis," Water Resources Management, Vol. 27, pp. 3697-3711.

[24] A. K. Lohani, et al., (2011) "Comparative study of neural network, fuzzy logic and linear transfer function techniques in daily rainfall-runoff modelling under different input domains," Hydrological Processes, Vol. 25, pp. 175-193.

[25] C. Wu \& K. Chau, (2011) "Rainfall-runoff modeling using artificial neural network coupled with singular spectrum analysis," Journal of Hydrology, Vol. 399, pp. 394-409.

[26] S. M. Kueh \& K. K. Kuok, (2016) "Precipitation downscaling using the artificial neural network BatNN and development of future rainfall intensity-duration-frequency curves," Climate Research, Vol. 68, pp. 73-89.

[27] T. Partal, H. Kerem Cigizoglu \& E. Kahya, (2015) "Daily precipitation predictions using three different wavelet neural network algorithms by meteorological data," Stochastic Environmental Research and Risk Assessment, Vol. 29, pp. 1317-1329.

[28] J. Osman, J. Inglada \& J. Dejoux, (2015) "Assessment of a Markov logic model of crop rotations for early crop mapping," Computers and Electronics in Agriculture, Vol. 113, pp. 234-243.

[29] M. Troffaes \& L. Paton, (2013) "Logistic regression on Markov chains for crop rotation modelling," in ISIPTA '13: proceedings of the eighth international symposium on imprecise probability : theories and applications 2013, Compiègne, France, pp. 329-336. 
[30] R. Y. Adam, (2016) "Stochastic Model for Rainfall Occurrence Using Markov Chain Model in Kurdufan State, Sudan," American Scientific Research Journal for Engineering, Technology, and Sciences (ASRJETS), Vol. 17, pp. 272-286.

[31] K. G. Mandal, J. Padhi, A. Kumar, S. Ghosh, D. K. Panda, R. K. Mohanty, \& M. Raychaudhuri, (2015) "Analyses of rainfall using probability distribution and Markov chain models for crop planning in Daspalla region in Odisha, India," Theoretical and Applied Climatology, Vol. 121, pp. 517-528.

[32] S. M. Deni, A. A. Jemain \& K. Ibrahim, (2009) "Fitting optimum order of Markov chain models for daily rainfall occurrences in Peninsular Malaysia," Theoretical and Applied Climatology, Vol. 97, pp. 109-121.

[33] A. G. Dastidar, D. Ghosh, S. Dasgupta \& U. K. De, (2010) "Higher order Markov chain models for monsoon rainfall over West Bengal, India," Indian Journal of Radio and Space Physics, vol. 39, pp. 39-44.

[34] M. Safouane, N. Saida, J. Sihem \& S. Mohamed, (2016) "Using the Markov Chain for the Generation of Monthly Rainfall Series in a Semi-Arid Zone," Open Journal of Modern Hydrology, Vol. 6, p. 51.

[35] Y. Wang, J. Liu, P. Wang, P. Han, D. Zhu \& S. Zhang, (2007) "Prediction of drought occurrence based on the standardized precipitation index and the Markov chain model with weights," Agricultural Research in the Arid Areas, Vol. 5, pp. 198-203.

[36] H. Tabari, R. Zamani, H. Rahmati \& P. Willems, (2015) "Markov chains of different orders for streamflow drought analysis," Water Resources Management, Vol. 29, pp. 3441-3457.

[37] D. Sonnadara \& D. Jayewardene, (2015) "A Markov chain probability model to describe wet and dry patterns of weather at Colombo," Theoretical and Applied Climatology, vol. 119, pp. 333-340.

[38] R. Singh, C. Patel, M. Yadav, P. Singh \& K. Singh, (2014) "Weekly rainfall analysis and Markov Chain Model probability of dry and wet weeks at Varanasi in Uttar Pradesh," Environment and Ecology, Vol. 32, pp. 885-890.

[39] V. Vamitha, M. Jeyanthi, S. Rajaram \& T. Revathi, (2012) "Temperature prediction using fuzzy time series and multivariate Markov chain," International Journal of Fuzzy Mathematics and Systems, Vol. 2, pp. 217-230.

[40] Y. Lu \& S. Qin, (2010) "Stored-grain insect image processing based on a Hidden Markov Model," in Electrical and Control Engineering (ICECE), 2010 International Conference on, pp. 1997-2000.

[41] Y. Shen, L. Di, L. Wu, G. Yu, H. Tang \& G. Yu, (2012) "Hidden Markov Models for corn progress percents estimation in multivariate time series," in Agro-Geoinformatics (Agro-Geoinformatics), 2012 First International Conference on, pp. 1-6.

[42] I. Pal, A. Robertson, U. Lall \& M. Cane, (2015) "Modeling winter rainfall in Northwest India using a hidden Markov model: understanding occurrence of different states and their dynamical connections," Climate Dynamics, Vol. 44, pp. 1003-1015.

[43] W. L. Tan, F. Yusof \& Z. Yusop, (2016) "Subseasonal to multidecadal variability of northeast monsoon daily rainfall over Peninsular Malaysia using a hidden Markov model," Theoretical and Applied Climatology, pp. 1-10.

[44] A. M. Greene, A. W. Robertson, P. Smyth \& S. Triglia, (2011) "Downscaling projections of Indian monsoon rainfall using a non-homogeneous hidden Markov model," Quarterly Journal of the Royal Meteorological Society, Vol. 137, pp. 347-359.

[45] F. Yusof, I. L. Kane \& Z. Yusop, (2015) "Measuring volatility persistence on rainfall records with the hybrid of autoregressive fractional integrated moving average (ARFIMA)-hidden Markov model (HMM)," in The 2nd ISM International statistical conference 2014 (ISM-II): Empowering the Applications of Statistical and Mathematical Sciences , pp. 446-452.

[46] G. Mallya, S. Tripathi, S. Kirshner \& R. Govindaraju, (2012) "Probabilistic assessment of drought characteristics using hidden Markov model," Journal of Hydrologic Engineering, Vol. 18, pp. 834845.

[47] G. Mallya, S. Tripathi, \& R. Govindaraju (2012) Hidden Markov model-based probabilistic assessment of droughts: Proquest, Umi Dissertation.

[48] M. Khadr, (2016) "Forecasting of meteorological drought using Hidden Markov Model (case study: The upper Blue Nile river basin, Ethiopia)," Ain Shams Engineering Journal, Vol. 7, pp. 47-56.

[49] J. Shena, M. Yanga, R Zhongb \& C. Zhangc., (2011) "A Hidden Markov Model Based Method for Anomaly Detection of Precipitation Series,".

[50] B. Pradhan \& S. Lee, (2010) "Landslide susceptibility assessment and factor effect analysis: backpropagation artificial neural networks and their comparison with frequency ratio and bivariate logistic regression modelling," Environmental Modelling \& Software, Vol. 25, pp. 747-759. 
[51] H. Chen, J. Zhang, Y. Xu, B. Chen, \& K. Zhang, (2012) "Performance comparison of artificial neural network and logistic regression model for differentiating lung nodules on CT scans," Expert Systems with Applications, Vol. 39, pp. 11503-11509.

[52] E. S. Elmolla, M. Chaudhuri \& M. M. Eltoukhy, (2010) "The use of artificial neural network (ANN) for modeling of COD removal from antibiotic aqueous solution by the Fenton process," Journal of hazardous materials, Vol. 179, pp. 127-134.

[53] B. Yang, L. Yab \& H. Huang, (2007) "Early software quality prediction based on a fuzzy neural network model," in Third International Conference on Natural Computation (ICNC 2007), pp. 760764.

[54] P. Bassi, E. Sacco, V. De Marco, M. Aragona \& A.Volpe, (2007) "Prognostic accuracy of an artificial neural network in patients undergoing radical cystectomy for bladder cancer: a comparison with logistic regression analysis," BJU international, Vol. 99, pp. 1007-1012.

[55] H. Navarro \& L. Bennun, (2014) "Descriptive examples of the limitations of artificial neural networks applied to the analysis of independent stochastic data," arXiv preprint arXiv:1404.5598.

[56] T. Ayer, J. Chhatwal, O. Alagoz, C. Kahn, R. Woods, \& E. Burnside, (2010) "Comparison of Logistic Regression and Artificial Neural Network Models in Breast Cancer Risk Estimation 1," Radiographics, Vol. 30, pp. 13-22.

[57] A. Degirmenci, (2014) "Introduction to Hidden Markov Models", Harvard University, pp 1-5.

[58] J. I. Figueroa-Angulo, J. Savage, E. Bribiesca, B. Escalante \& L. E. Sucar, (2015) "Compound Hidden Markov Model for Activity Labelling," International Journal of Intelligence Science, Vol. 5, p. 177.

[59] S. Bhardwaj, V. Sharma, S. Srivastava, O.S. Sastry, B. Bandyopadhyay, S.S. Chandel \&J.R.P. Gupta, (2013) "Estimation of solar radiation using a combination of Hidden Markov Model and generalized Fuzzy model," Solar Energy, Vol. 93, pp. 43-54.

[60] M. J. Johnson \& A. S. Willsky, (2013) "Bayesian nonparametric hidden semi-Markov models," Journal of Machine Learning Research, Vol. 14, pp. 673-701.

[61] T. Marwala, U. Mahola \& F.V Nelwamondo, (2006) "Hidden Markov models and Gaussian mixture models for bearing fault detection using fractals," in The 2006 IEEE International Joint Conference on Neural Network Proceeding, pp. 3237-3242.

[62] S. K. Gaikwad, et al., "A review on speech recognition technique," International Journal of Computer Applications, vol. 10, pp. 16-24, 2010.

[63] C. Lampros, C. Papaloukas, T. P. Exarchos, Y. Goletsis \& D. I. Fotiadis , (2007) "Sequence-based protein

structure prediction using a reduced state-space hidden Markov model,"Computers in Biology and Medicine, Vol. 37, pp. 1211-1224.

[64] O Netzer, JM Lattin \& V Srinivasan, "A hidden Markov model of customer relationship dynamics," Marketing Science, Vol. 27, pp. 185-204, 2008.

[65] T. Liu, "Application of Markov chains to analyze and predict the time series," Modern Applied Science, Vol. 4, p. 162, 2010.

[66] W. K Ching, M. K Ng \& E. S Fung, "Higher-order multivariate Markov chains and their applications," Linear Algebra and its Applications, Vol. 428, pp. 492-507, 2008.

[67] G. Bolch, S. Greiner, H. de Meer \& K. S. Trivedi (2006) Queueing networks and Markov chains: modeling and performance evaluation with computer science applications: John Wiley \& Sons.

[68] S. M. Ross (2014) Introduction to probability models: Academic press.

[69] P. Skalny \& B. Krajc, (2013) "Discrete-Time Markov Chains in Reliability Analysis-Case Study," in International Joint Conference CISIS'12-ICEUTE'12-SOCO’12 Special Sessions, pp. 421-427.

[70] M. S. Swaminathan, (2014) "Modelling of Dynamic Change in Ecosystems," M S Swaminathan Research Foundation, Chennai, India, 2014.

[71] J. Koehler Leman, M. B. Ulmschneider \& J. J. Gray, (2015) "Computational modeling of membrane proteins," Proteins: Structure, Function, and Bioinformatics, Vol. 83, pp. 1-24.

[72] A. Sadhu, G. Prakash \& S. Narasimhan, (2016) "A hybrid hidden Markov model towards fault detection of rotating components," Journal of Vibration and Control, pp 1-21.

[73] E. Trentin \& M. Gori, "A survey of hybrid ANN/HMM models for automatic speech recognition," Neurocomputing, Vol. 37, pp. 91-126, 2001.

[74] P. Jiang and X. Liu, (2016) "Hidden Markov model for municipal waste generation forecasting under uncertainties," European Journal of Operational Research, Vol. 250, pp. 639-651. 
[75] M. R. Hassan \& B. Nath, (2005) "Stock market forecasting using hidden Markov model: a new approach," in Intelligent Systems Design and Applications, 2005. ISDA'05. Proceedings. 5th International Conference on, pp. 192-196.

[76] O. Erkaymaz, M. Özer \& N. Yumuşak, (2014) "Impact of small-world topology on the performance of a feed-forward artificial neural network based on 2 different real-life problems," Turkish Journal of Electrical Engineering \& Computer Sciences, Vol. 22, pp. 708-718.

[77] K. Were, D. Tien Bui, Ø. B. Dick \& B. Singh, (2015) "A comparative assessment of support vector regression, artificial neural networks, and random forests for predicting and mapping soil organic carbon stocks across an Afromontane landscape," Ecological Indicators, Vol. 52, pp. 394-403.

[78] A. Krenker, J. Bešter \& A. Kos (2011) Introduction to the artificial neural networks: INTECH Open Access Publisher.

[79] T. Akinci, (2015) "Short term wind speed forecasting with ANN in Batman, Turkey," Elektronika ir Elektrotechnika, Vol. 107, pp. 41-45.

[80] M. Khashei \&M. Bijari, (2010) "An artificial neural network (p, d, q) model for timeseries forecasting," Expert Systems with Applications, Vol. 37, pp. 479-489.

[81] L. Ekonomou, (2010) "Greek long-term energy consumption prediction using artificial neural networks," Energy, Vol. 35, pp. 512-517.

[82] D. Striccoli, G. Boggia \& L. Grieco, (2015) "A Markov model for characterizing IEEE 802.15. 4 MAC layer in noisy environments," Industrial Electronics, IEEE Transactions on, Vol. 62, pp. 51335142.

[83] W. Jamal, S. Das, I. Opresu \& K. Maharatna, (2015) "Prediction of synchrostate transitions in EEG signals using Markov chain models," Signal Processing Letters, IEEE, Vol. 22, pp. 149-152.

[84] D. Simon, M. Ergezer, D. Du \& R. Rarick, (2011) "Markov models for biogeography-based optimization," Systems, Man, and Cybernetics, Part B: Cybernetics, IEEE Transactions on, Vol. 41, pp. 299-306.

[85] M. Zheng, B. Zheng \& H. Zhang, (2015) "Feasibility Research of Infinite State Markov Chain Technique in Variable-frequency Speed Control System," in 2015 International Industrial Informatics and Computer Engineering Conference.

[86] E. Coviello, A. B. Chan \& G. R. G. Lanckriet, (2014) "Clustering hidden Markov models with variational HEM," The Journal of Machine Learning Research, Vol. 15, pp. 697-747.

[87] C. Kohlschein, (2006) "An introduction to hidden Markov models," in Probability and Randomization in Computer Science. Seminar in winter semester.

[88] D. P. A. Mackworth, (2010) "Hidden Markov Models," Artificial Intelligence Foundatioon of Computational Agents.

[89] K. Tumilaar, Y. Langi \& A. Rindengan , (2015) "Hidden Markov Model," de CARTESIAN, Vol. 4, pp. 86-94.

[90] P. Dymarski, (2011) "Hidden Markov Models, Theory and Applications," InTech Open Access Publishers.

[91] M. H. Kabir,M. R. Hoque, K. Thapa, \& S. Yang, (2016) "Two-Layer Hidden Markov Model for Human Activity Recognition in Home Environments," International Journal of Distributed Sensor Networks, Vol. 2016, pp 1-12.

[92] I.A.Adeyanju, O.S Ojo, \& E.O Omidiora, (2016) "Recognition of Typewritten Characters Using Hidden Markov Models," British Journal of Mathematics \& Computer Science, Vol. 12, p. 1.

[93] M. O. Mendez, M. Matteucci, V. Castronovo, L. Ferini-Strambi, S. Cerutti \& A. Bianchi , (2010) "Sleep staging from Heart Rate Variability: time-varying spectral features and Hidden Markov Models," International Journal of Biomedical Engineering and Technology, Vol. 3, pp. 246-263.

[94] M. Siu, H. Gish, A. Chan, W. Belfield \& S. Lowe, (2014) "Unsupervised training of an HMM-based self-organizing unit recognizer with applications to topic classification and keyword discovery," Computer Speech \& Language, Vol. 28, pp. 210-223.

[95] A. Das \&M. Hasegawa-Johnson, (2015) "Cross-lingual transfer learning during supervised training in low resource scenarios," in Sixteenth Annual Conference of the International Speech Communication Association, 2015. 


\section{AUTHORS}

Johevajile K. Mazima was born in Bukoba, Tanzania in 1972. He obtained his BE degree in Electronics and Communication Engineering from St. Joseph University in Tanzania in 2009, MSc degree in Information and Communication Science and Engineering from Nelson Mandela African Institution of Science and Technology in 2013. Currently, he is pursuing $\mathrm{PhD}$ in Electronics and Telecommunication Engineering at Nelson Mandela African Institution of Science and Technology, Tanzania. His research interests are in the areas of wireless technology, sensing technologies and transmission systems.

Dr.Johnson I. Agbinya was born in Nigeria. He obtained his Bachelor degree in Electronics and Electrical Engineering from the University of Ife, Nigeria in 1977. He received his MSc in Electronic Communications from the University of Strathclyde, in Glasgow, Scotland in 1982. And then, he obtained PhD in Electronic Communication Engineering from La Trobe University, in Bundoora, Australia in 1994. Before joining MIT he was an Associate Professor at La Trobe University. Prior to this he was a Senior

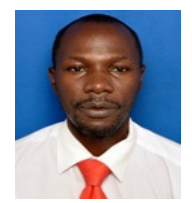
Lecturer at the University of Technology Sydney, Principal engineer (research) at Vodafone Australia and Senior Research Scientist at CSIRO Telecommunications and Industrial Physics (now CSIRO ICT). His research interests include remote sensing, sensors, mobile and broadband communications, sensor devices, networks, wireless power transfer and transmission systems. He is an Associate Professor and Head of School of Information Technology and Engineering, Melbourne Institute of Technology, in Melbourne, Australia He is the member of ACS, Nigerian Society of Engineers and Fellow of African Scientific Institute University of New Brunswick, Canada.

Dr.Emmanuel C. Manasseh was born in Tanga, Tanzania in 1979. He obtained his BSc degree in Telecommunication Engineering from the University Dar es Salaam, Tanzania in 2005. He received his ME degree in Telecommunication from Hiroshima University, Japan in 2010. And then, he obtained $\mathrm{PhD}$ in Telecommunication Engineering from Hiroshima University, Japan in 2013. Before joining TCRA, he was a Lecturer at Nelson Mandela African Institution of Science and Technology in Tanzania. And before Nelson

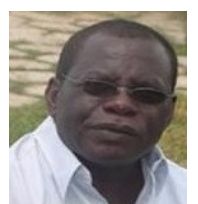
Mandela, he was an Assistant Professor at Hiroshima University. He once worked with Celtel Mobile Phone Company in Tanzania as a BSS Engineer before leaving for further studies in Japan. His research interests include artificial complex systems engineering, signal processing, wireless sensor networks, mobile communication, remote Sensing and Sensor devices.He is a Principal Research Officer at Tanzania Communication Regulatory Authority, Tanzania. Apart from IEEE membership, he is the ERB, IET, EURASIP, and APSIPA member.

Dr.Shubi F. Kaijage was born in Dar es Salaam, Tanzania. He obtained his Bachelor degree in Electronics and Electrical Engineering from the University of Dar es Salaam, Tanzania. He received his $\mathrm{MSc}$ and $\mathrm{PhD}$ in Telecommunication Engineering from Shenzhen University, Ryukyus, China. His research interests include wireless communications.He is the Head of Department of Communication Science and Engineering, at Nelson Mandela African Institution of Science and Technology, in Arusha, Tanzania. 